\title{
Modeling of the effect of a high-pressure jet of cement mortar on the surrounding soil environment when performing jet grouting columns using jet technology
}

\author{
Natalia Zuievska ${ }^{1}$, Valentyna Gubashova ${ }^{2}$, and Valentyn Korobiichuk ${ }^{3}$ \\ ${ }^{1}$ National Technical University of Ukraine "Igor Sikorsky Kyiv Polytechnic Institute”, 37 Peremohy Ave., Kyiv, 03056, Ukraine \\ ${ }^{2}$ LLC JV Osnova-Solsif, Department of special hydravlic works, 17 Kovpaka Str., Kyiv, 03150, Ukraine \\ ${ }^{3}$ Zhytomyr Polytechnic State University, 103 Chudnivska Str., Zhytomyr, 10005, Ukraine
}

\begin{abstract}
The main idea of jet grouting technology is the implementation of processes aimed at changing the characteristics of soils, creating materials with the necessary properties on their basis and forming underground elements with specified parameters from these materials. The high pressure of the cement mortar jet leads to soil blending and its continuous destruction within the radius of impact of the jet. According to some authors, the jet outside the destructive radius does not affect the surrounding soil environment. In compliance with practical studies performed at construction sites in Kyiv, Ukraine, the data on changes in the physical and mechanical characteristics of the soil surrounding the soil-cement column were obtained. This fact led to a more detailed study of the effect of a high-pressure jet on the surrounding soil during the execution of columns using jet technology.
\end{abstract}

\section{Introduction}

Jet grouting is the destruction of the structure of the soil or soft rock and blending or partial replacement of it with a cementitious substance, while the destruction of the soil occurs due to a liquid jet with high energy, and the liquid itself performs a cementing function [1].

The research of the phenomenon of destruction of the natural structure and soil blending by jet grouting is wellknown and provided by many scientists [2-27].

Jet grouting technology allows it to be used in solving various tasks of underground construction, namely: underground load-bearing and anti-filtration structures, horizontal or inclined slabs, elements of buildings and structures, artificial basements, walls and floors of sunk premises, including underground garages, the installation of roots of ground anchors, when strengthening the pinning of existing buildings and structures, retaining walls, pit fences, horizontal underground anti-filtration screens, anti-landslide structures, fixing ground massifs for sinking underground tunnels, wells of large diameter with bottoms and many other structures. Jet grouting elements are also used for reinforcing ground bases in earthquake-prone areas.

A high-pressure jet, striking the ground, destroys its original structure and according to Kanematsu research [28] the zones of a high-pressure jet (in the experimental work of a water jet) are: zone 1 - the core, the hydrodynamic pressure in which is constant, zone $2-$ an intermediate zone and, as a rule, the distance to the end of zone 2 is 300 nozzle diameters, zone 3 , where the flow loses focus, becomes intermittent and cavitation effects begin to prevail.

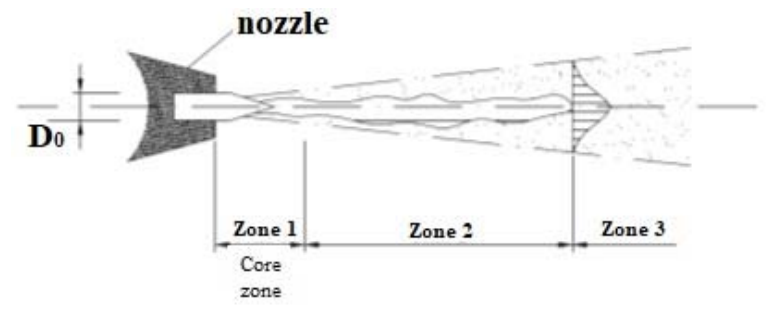

Fig. 1. Characteristics of the water jet according to Kanematsu.

The distribution of hydrodynamic pressure in zone 3 along the jet axis decreases with exponential distance. If you release a jet of water into a dense environment or clean water, it appears that zone 3 does not exist. This circumstance is typical for most cases of jet grouting.

The high pressure leads to soil blending and its continuous destruction within the radius of impact of the jet. Therefore, based on his findings, Kanematsu suggested that the use of jet grouting does not affect the stress-strain state in the soil beyond the impact radius. In fact, even when working with very high pressure, the injection process only leads to an increase in pressure within the collapsing area (zone 1 and 2). The same opinion is supported by C. S. Covil and A. E. Skinner [10].

At the same time, practicing organizations, based on experimental data, have shown that the implementation of jet grouting elements of circular cross-section affects the surrounding soil mass outside these elements. 
Consolidamenti E Pali in Italy performed a series of laboratory tests of the soil surrounding the well made of intersecting jet injection columns (Fig. 2).

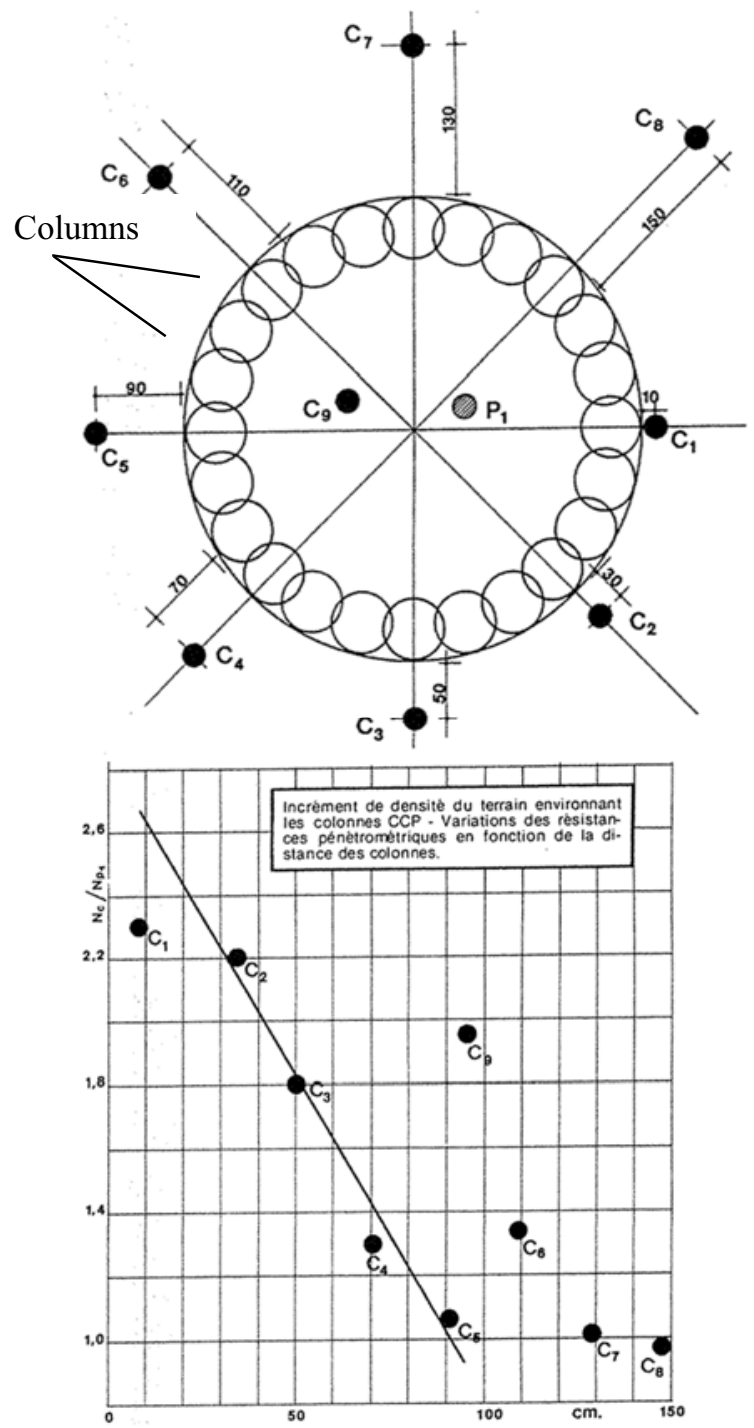

Fig. 2. Soil density around the jet grouting column depending on the radial distance.

The maximum effect of the high-pressure jet on the surrounding soil mass is observed at a distance of 10 and $30 \mathrm{~cm}$ (samples $\mathrm{C}_{1}$ and $\mathrm{C}_{2}$ ), the maximum effect on the physical and mechanical characteristics of the soil is observed at a distance of $110 \mathrm{~cm}\left(\mathrm{C}_{6}\right), 130 \mathrm{~cm}\left(\mathrm{C}_{7}\right)$ and 150 $\mathrm{cm}\left(\mathrm{C}_{8}\right)$.

\section{Research methods and results}

During the implementation of the project to strengthen the ground base of the historical monument of architecture, St. Andrew's Church, in Kyiv, studies of soil samples from the space between jet grouting columns were performed. Physical and mechanical examination of the selected soil samples showed that there is a zone with improved characteristics around the column. The density of soil (sandy loam) increased from $1.6 \mathrm{t} / \mathrm{m}^{3}$ to $1.65 \ldots 1.67 \mathrm{t} / \mathrm{m}^{3}$, and the impact zones reached $30 \mathrm{~cm}$ from the surface of the column. Analysis of experimental data and comparison with the statements of some authors about the absence of influence on the surrounding soil actuate the question of the future studying the effects of the implementation of jet grouting elements on the surrounding soil environment.

A jet of cement mortar coming out under high pressure from the nozzle located on the hydraulic monitor rotates and destroys the surrounding soil, mixing it with the cement mortar. If at the first rotation the jet destroys the soil, then at the second rotation the jet is already in the cement mortar and can be considered as a drowned jet of liquid.

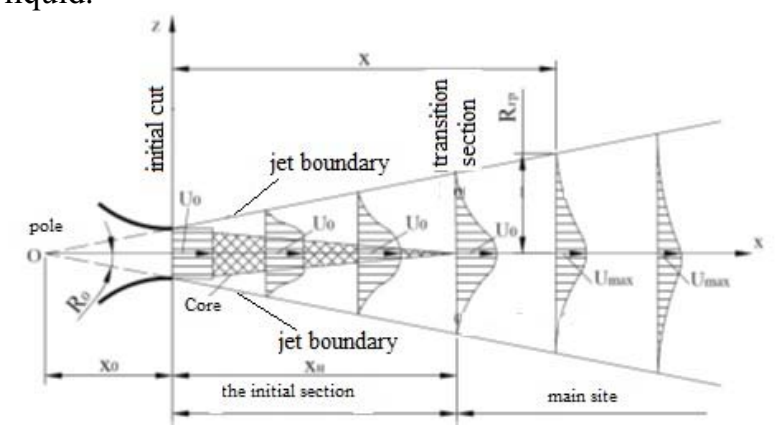

Fig. 3. Diagram of a drowned free turbulent jet.

For the design scheme, the nozzle radius is $\mathrm{R}_{0}=1.2 \mathrm{~mm}$ (the nozzle diameter located on the hydraulic monitor is $2.4 \mathrm{~mm}$ )

Speed of the cement mortar jet at the nozzle outlet:

$$
U_{0}=\frac{4 \cdot Q_{p} /\left(\pi \cdot d_{c}{ }^{2}\right)}{n_{c}}=\frac{(400 \cdot 100) /\left(6 \cdot 3,1416 \cdot 2,4^{2}\right)}{2}=184 \mathrm{~m} / \mathrm{s}
$$

Given that the diameter of the soil-cement column is $0.6 \mathrm{~m}$, the destructive radius is $x=0.3 \mathrm{~m}$.

Speed on the axis of the main section:

$$
U_{\text {max }}=\frac{0.96}{\frac{a \cdot x}{R_{0}}+0.29} U_{0}=\frac{0,96}{\frac{0,08 \cdot 0,3}{1,2 \cdot 10^{-3}+0,29}} 184=8,71 \frac{\mathrm{m}}{\mathrm{s}}
$$

where $a$ is the structural coefficient of 0.08 .

Half of the height of the jet at a distance of $x=0.3 \mathrm{~m}$ from the nozzle:

$$
\begin{gathered}
R=\left(3.4 \frac{a \cdot x}{R_{0}}+1\right) R_{0}= \\
=\left(3.4 \frac{0.08 \cdot 0.3}{1,2 \cdot 10^{-3}}+1\right) 1,2 \cdot 10^{-3}=0.083 \mathrm{~m}
\end{gathered}
$$

Based on the fact that we know the fracture radius of the jet, to calculate the residual pressure acting on the surrounding soil that has not been destroyed, we calculate the hydrodynamic pressure of the liquid jet on the wall:

$$
P=\rho_{p} \omega U^{2}=1500 \frac{3,14 \cdot 0,166^{2}}{4} 8,71^{2}=2458 H
$$

where $\rho_{p}$ is the density of the solution, $\omega$ is the crosssection of the flow, and $U$ is the average flow rate of the liquid.

When calculating the jet per $1 \mathrm{~m}^{2}$, we obtain a residual hydrodynamic pressure of $P=113.8 \mathrm{kN} / \mathrm{m}^{2}$. 
The calculated data of the residual pressure that causes a high-pressure jet of cement mortar on the surrounding soil are used to create a model in the Plaxis 3D Foundation software package.

Engineering and geological characteristics of the soil and geometric characteristics of jet grouting columns made using jet technology are taken on the example of the object "strengthening foundations during the reconstruction of St. Andrew's Church in Kyiv", on the territory of which experiments were conducted on soil samples taken in the intercolumnar space.

The design solution for strengthening the foundations of St. Andrew's church was developed in 2009 and it was the implementation of soil-cement columns in the base from the middle of the under-porch, from the outside of the stylobate and from the middle of the church and stylobate premises with a total of 259 pieces, a length of 10.8 to $13.5 \mathrm{~m}$ with angles of inclination from $7^{\circ}$ to $13^{\circ}$ and a diameter of $600 \mathrm{~mm}$ with an extension of $800 \mathrm{~mm}$, a step of 1.0-2.7 m. A schematic diagram of strengthening the foundations of the church is shown in Figure 4:

We accept the Mohr-Coulomb model for the soil and body material of the jet grouting column. To simulate the process of performing a jet grouting column and the effect on the surrounding soil, the column material is given low characteristics to reflect its liquid state.

The thickness of the experimental layer in which the samples were taken is IGE $-4-8 \mathrm{~m}$. In the column model $-5 \mathrm{~m}$ and there is still $3 \mathrm{~m}$ under the columns. The introduction of soils below the experimental layer would not give a result, since they did not take soil samples, that is, it would be a mistake to compare them with the experimental results and assert the correctness of the simulated data obtained.

Characteristics of solid sandy loam: $\gamma=1.6 \mathrm{t} / \mathrm{m}^{3}$, $\phi=23^{\circ}, \mathrm{c}=33 \mathrm{kPa}, \mathrm{E}=17 \mathrm{MPa}$. Characteristics of the jet grouting column: $\gamma=1.55 \mathrm{t} / \mathrm{m}^{3}, \phi=3^{\circ}, \quad \mathrm{c}=3 \mathrm{kPa}$, $\mathrm{E}=0.15 \mathrm{MPa}$.

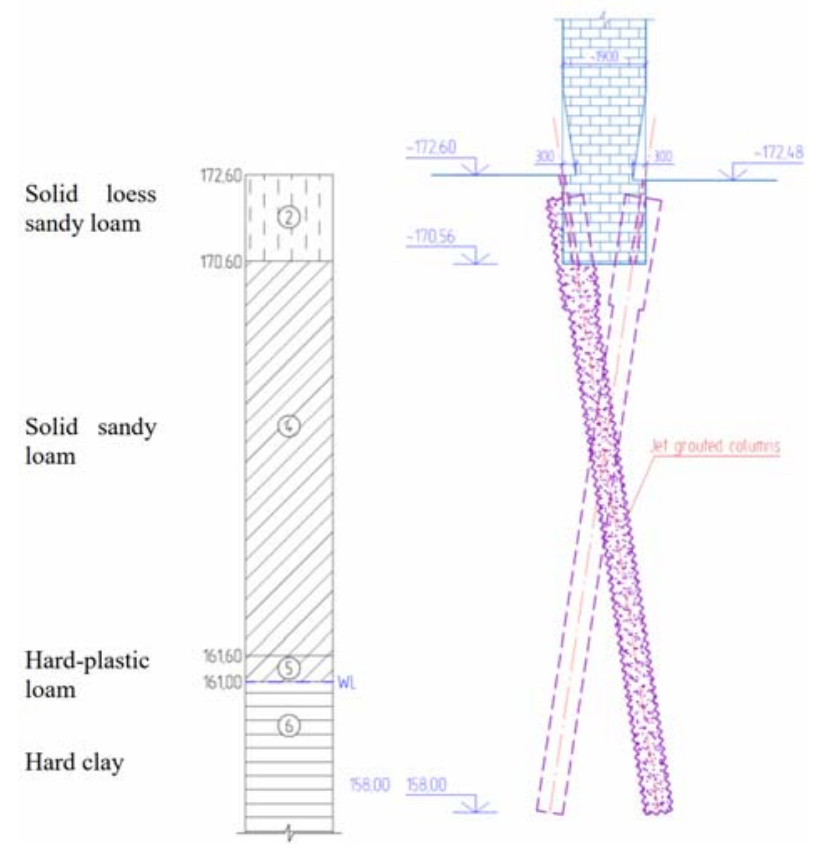

Fig. 4. Schematic diagram of strengthening foundations.
The model is the 5 meter column, the diameter is $0.6 \mathrm{~m}$, the intercolumnar distance is $0.85 \mathrm{~m}$, the pinning is brick, the depth is $2 \mathrm{~m}$. The study of soil samples took place from the basement at a foundation depth of $2 \mathrm{~m}$, the level of occurrence of the selected soil samples $-2.5 \mathrm{~m}$ from the basement floor level. In accordance with the software capabilities of the geotechnical design complex, the jet grouting columns are set vertical.

The main purpose of the simulation was to study the effect of the residual pressure of a high-pressure jet of cement mortar, a pressure that is directed horizontally. The platform for research is the inter-column space, and therefore only two columns are introduced in the model. That is, with the same soil environment, the same distance and the same residual pressure value (constant technological parameters when performing a column), the results of exposure in the inter-column space would also be the same.

The model reproduces experimental conditions: pitch, soil, depth of occurrence of the selected samples.

A calculated residual pressure $P=113.8 \mathrm{kN} / \mathrm{m}^{2}$ is applied along the contour of the surface of the jet grouting column.

Figure 5 shows the deformed grid of the created model and the total displacements that occur in it. The maximum value of the total displacement is $8.5 \mathrm{~mm}$ and it occurs on the surface of the jet grouting column, and figure 5 clearly separates the deformation zones, i.e. the zones of impact that arise from the residual pressure of a high-pressure jet of cement mortar. The dimensions of these zones are 29.5 and $26.5 \mathrm{~cm}$ (Fig. 6). In comparison with the experimental data obtained during the study of soil samples taken in the intercolumnar space, the maximum impact zones were 15 and $30 \mathrm{~cm}$ from the surface of the first and second jet grouting columns.

If we select a single volume of deformed soil in the column space, we can calculate the change in the volume weight of the soil.

Soil density:

$$
\gamma=\frac{m}{V}
$$

Let's denote $\gamma_{1}, V_{1}$ the density and volume of soil before the columns are made, which is equal to $1.6 \mathrm{t} / \mathrm{m}^{3}$, $\gamma_{2}, V_{2}$ is the soil that was compacted. Let's assume that the weight of the soil has not changed and equate the density expression for the first and second soils:

$$
\begin{gathered}
\gamma_{1} V_{1}=\gamma_{2} V_{2}, \text { hence } \\
\gamma_{2}=\frac{\gamma_{1} V_{1}}{V_{2}}=\frac{1,6 \cdot(0,295 \cdot 1 \cdot 1)}{(0,295-0,008) \cdot 1 \cdot 1}=1,65 \mathrm{t} / \mathrm{m}^{3}
\end{gathered}
$$

Returning to the results of testing soil samples from the object "reconstruction of St. Andrew's church", the density of the selected soil varied from 1.64 to $1.67 \mathrm{t} / \mathrm{m}^{3}$. As a result of modeling the impact of performing jet grouting columns, the value (7) of changes in soil density from the impact zone was obtained $-1.65 \mathrm{t} / \mathrm{m}^{3}$, which corresponds to experimental data (table 1).

When studying the object of reconstruction of St. Andrew's church, numerical values of the zone of influence equal to 15 and $30 \mathrm{~cm}$ were obtained, and the 
following results were obtained during modeling: 29.5 and $26.5 \mathrm{~cm}$, corresponding to full-scale experiments. The results obtained in accordance with the simulation and experimental data are entered for comparison in Table 1.
Figures 7-9 show the effect of performing a jet grouting column using jet geotechnology on the stressstrain state of the surrounding soil environment.
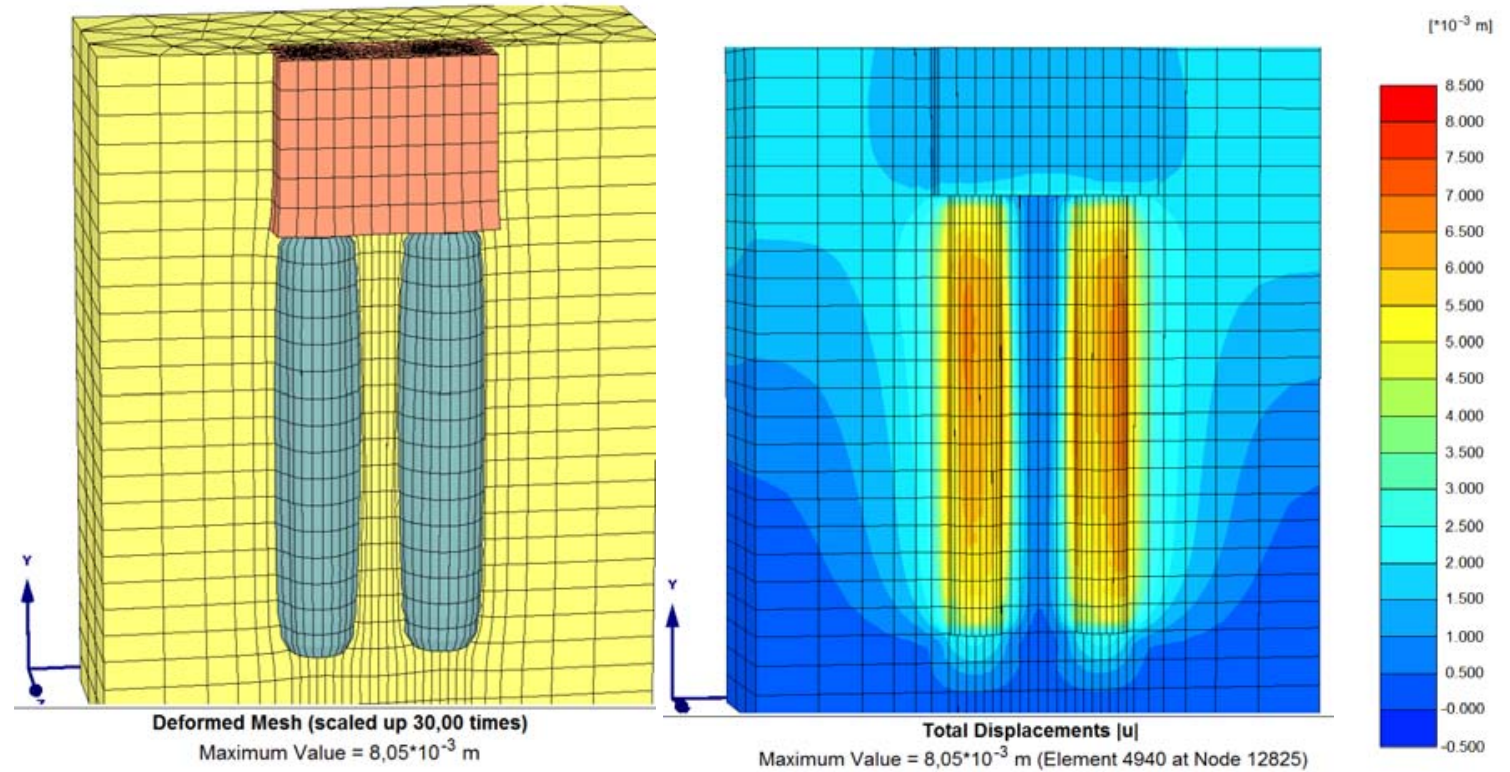

Fig. 5. Deformed finite element grid of the calculated model.

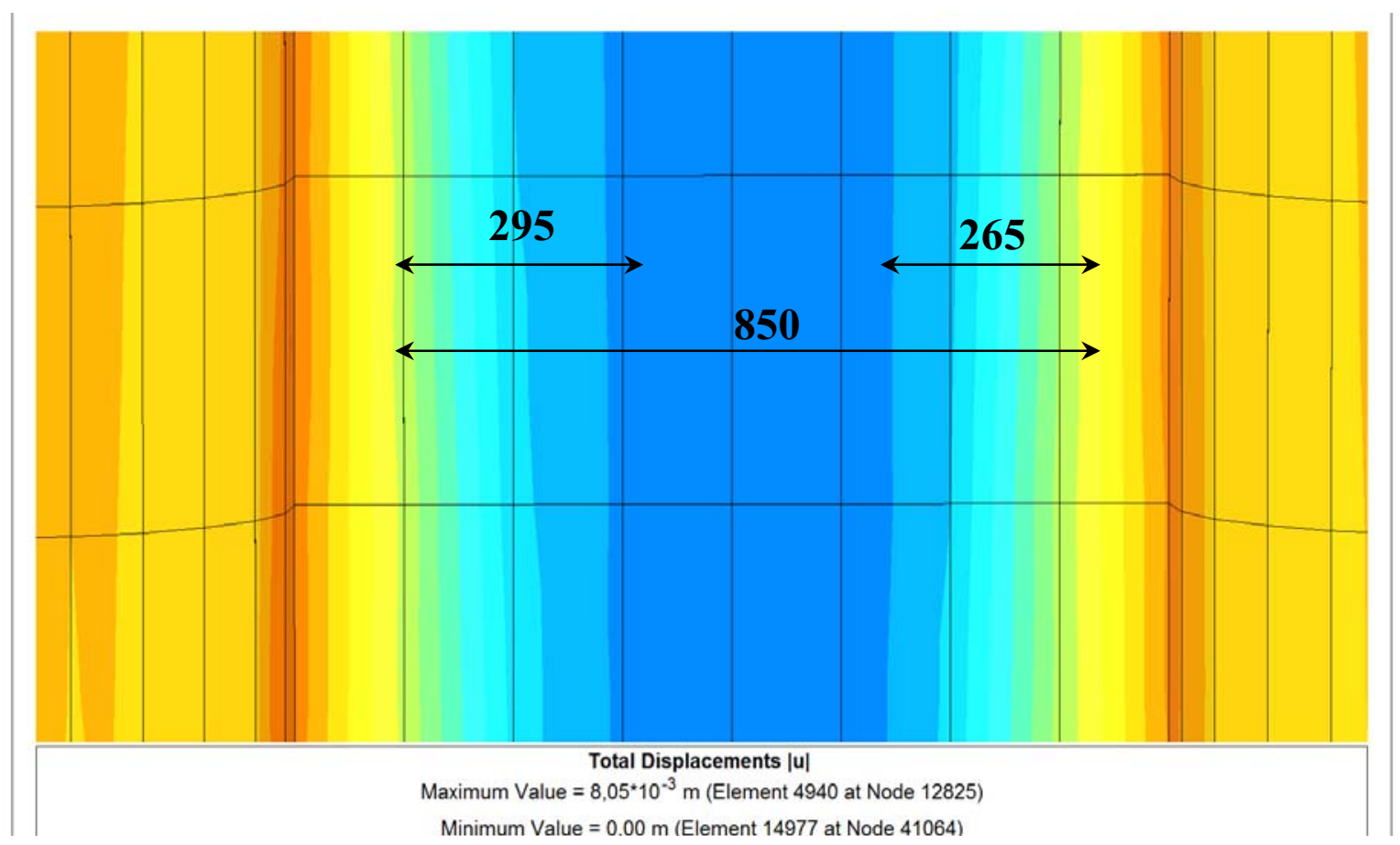

Fig. 6. Zone of influence on the soil in the intercolumnar space.

Table 1. Comparison of research results and results obtained during modeling.

\begin{tabular}{|c|c|c|c|c|c|}
\hline Soil Type & $\begin{array}{c}\text { The density of the } \\
\text { soil sample intact } \\
\text { structure }\end{array}$ & \multicolumn{2}{|c|}{$\begin{array}{c}\text { Density of soil samples, after } \\
\text { accomplishment of soil-cement columns }\end{array}$} & $\begin{array}{c}\text { The sizes of zones of influence on } \\
\text { a soil massif }\end{array}$ \\
\cline { 3 - 6 } & $1,6 \mathrm{t} / \mathrm{m}^{3}$ & $1,64 \ldots 1,67 \mathrm{t} / \mathrm{m}^{3}$ & $1,65 \mathrm{t} / \mathrm{m}^{3}$ & 15 and $30 \mathrm{~cm}$ & 26,5 and $29,5 \mathrm{~cm}$ \\
\hline $\begin{array}{c}\text { Sand of solid } \\
\text { consistency }\end{array}$ & rimulation results & research data & $\begin{array}{c}\text { according to the } \\
\text { simulation } \\
\text { results }\end{array}$ \\
\hline
\end{tabular}




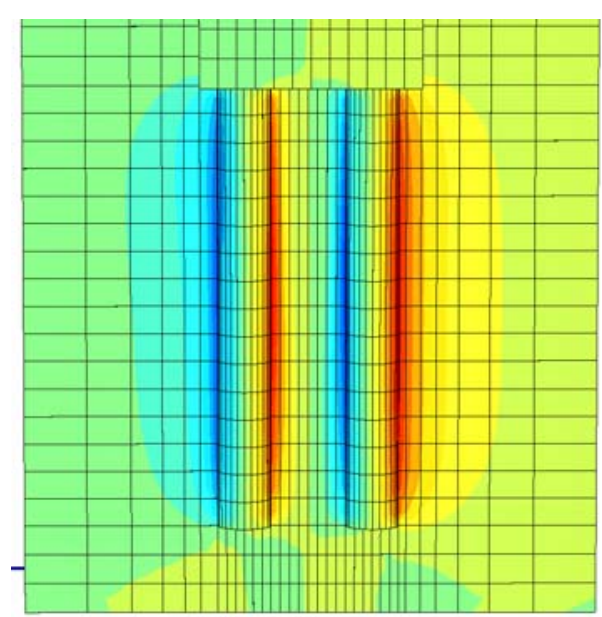

Total Displacements $\mathbf{u}_{\mathrm{x}}$

Maximum Value $=6.93 \cdot 10^{-3} \mathrm{~m}$ (Element 7723 at Node 20624) Minimum Value $=-6,73 \cdot 10^{-3} \mathrm{~m}$ (Element 7718 at Node 20796)

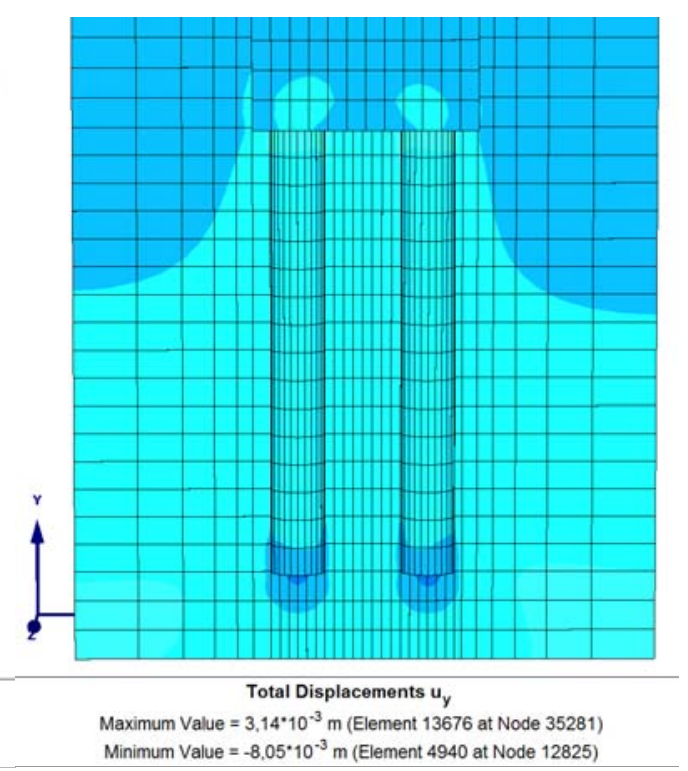

Fig. 7. Horizontal and vertical model movements.

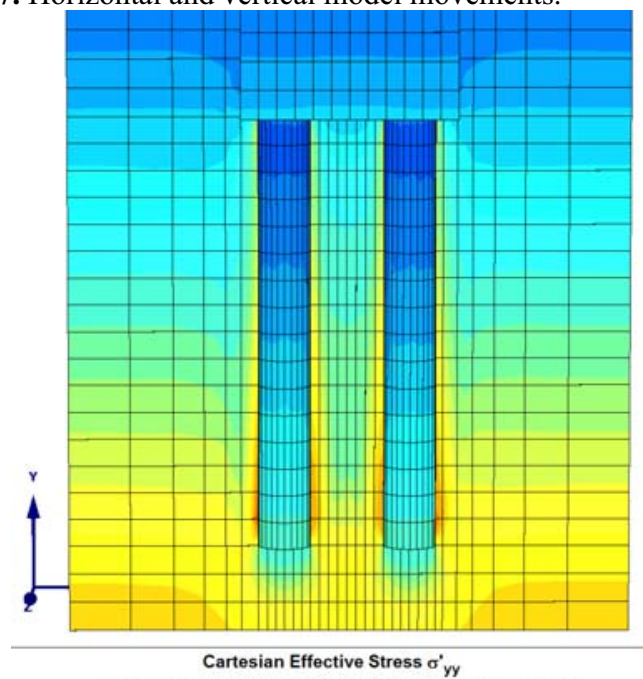

Maximum Value $=362,94^{*} 10^{-3} \mathrm{kN} / \mathrm{m}^{2}$ (Element 7 at Node 615 ) Minimum Value $=-176,16 \mathrm{kN} / \mathrm{m}^{2}$ (Element 12824 at Node 33937 )

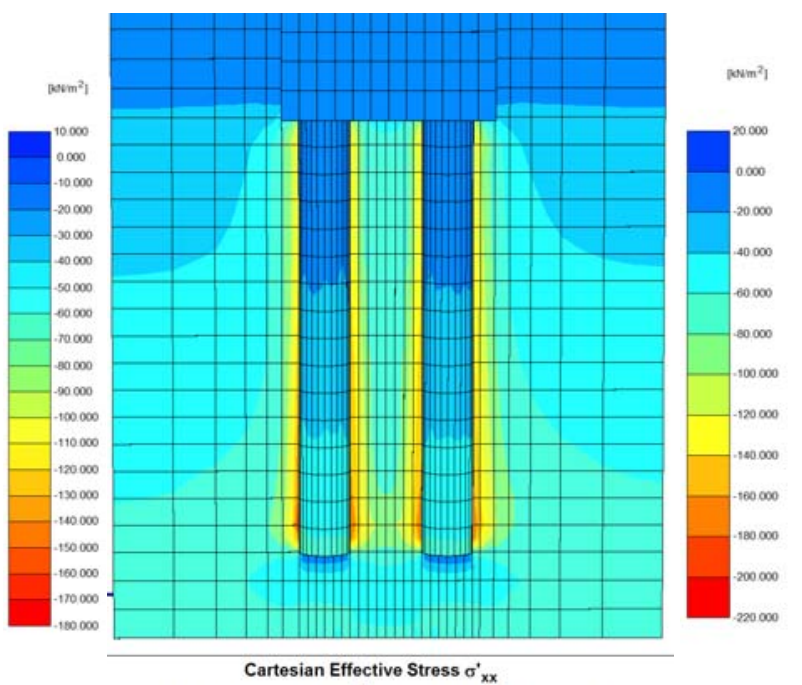

Maximum Value $=18.61 \mathrm{kN/m}{ }^{2}$ (Element 14275 at Node 36258$)$ Minimum Value $=-209,68 \mathrm{kN} / \mathrm{m}^{2}$ (Element 12722 at Node 33792)

Fig. 8. Vertical $\sigma_{y y}$ and horizontal $\sigma_{x x}$ effective stresses.

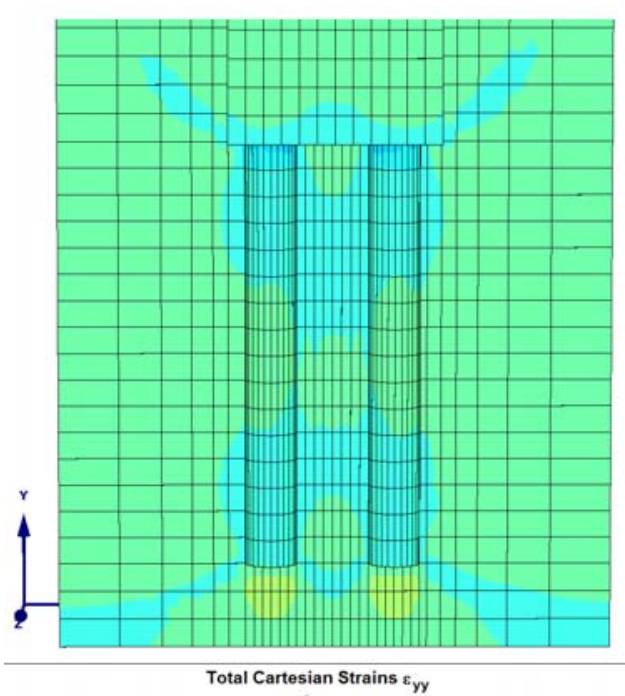

Maximum Value $=17.91 \cdot 10^{-3}($ Element 4311 at Node 10714) Minimum Value $=-11,27 * 10^{-3}$ (Element 12974 at Node 33763)

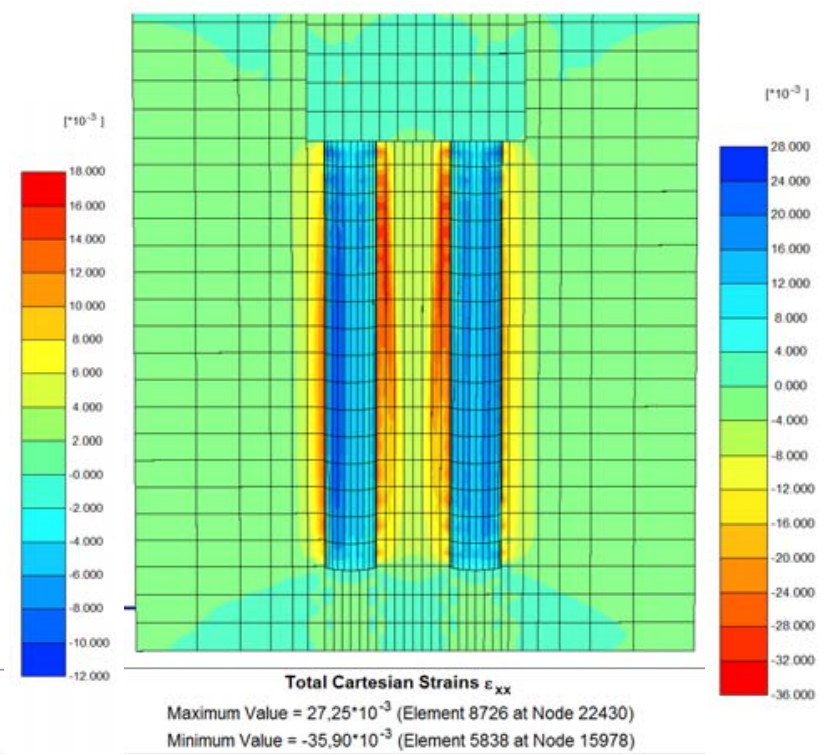

Fig. 9. Vertical $\varepsilon_{y y}$ and horizontal $\varepsilon_{x x}$ soil deformations. 


\section{Conclusions}

To perform numerical modeling of the formation of zones with improved physical and mechanical characteristics in soil massifs, a hydraulic calculation of the drowned jet of cement mortar was performed. Using research data from the described construction sites and knowing the destructive radius of the jet, the residual pressure that causes a high-pressure jet of cement mortar on the surrounding soil mass is calculated after the destructive energy is spent on the destruction and removal of the soil during the formation of the jet grouting column.

The obtained residual pressure calculations were used to create a model in the Plaxis 3D Foundation software package.

In accordance with the research data on the object of reconstruction of St. Andrew's church, Kyiv, the zones of influence on the surrounding soil environment were 15 and $30 \mathrm{~cm}$, and the simulation obtained results are 29.5 and $26.5 \mathrm{~cm}$.

As a result of modeling the impact of performing jet grouting columns, the value of the change in soil density from the impact zone was obtained - 1.65 $\mathrm{t} / \mathrm{m}^{3}$ (before the impact of the jet $1.60 \mathrm{t} / \mathrm{m}^{3}$ ), which corresponds to experimental data (the change in soil density after performing jet grouting columns on the construction site varied from 1.64 to $1.67 \mathrm{t} / \mathrm{m}^{3}$ ).

A field study and simulations performed to study the impact proved the presence of improved soil zones around the jet grouting columns.

\section{Reference}

1. EN 12716:2001 Execution of special geotechnical works. Jet grouting.

2. G. Miki, Soil improvement by jet grouting, in Proc. 3rd Int. GSSIM, (Singapore, 1985), pp. 45-52.

3. G. Miki, W. Nakanishi, Technical progress of jet grouting method and its newest type (PICSSRR, Paris, 1984), pp. 195-200

4. J. Morey, D.W. Campo, Quality control of jet grouting on the Cairo metro. Gr. Imp. 3 (2), 67 75 (1999). doi:10.1680/gi.1999.030203

5. M. Shibazaki, State of practice of jet grouting. Geotechnical Special Publication No. 120: GGT. 1, 198-217 (2003)

6. M. Shibazaki, M. Yokoo, H. Yoshida, Development oversized Jet Grouting, in GGT. Proceedings of the Third International Conference, vol. 1 (1999), pp. 294-302

7. J.L. Kauschinger, E.B. Perry, R. Hankour, Jet grouting: state-of-the-practice. ASCE Geotech. Spec. Publ. 1(30), 169-181 (2003)
8. J.L. Kauschinger, R. Hankour, E.B. Perry, Methods to estimate composition of Jet Grout bodies. ASCE Geotech 1 (30), 194-205 (2004)

9. A.L. Bell, Jet grouting. Ground Improvement, ed. by M.P. Moseley (Blackie, 1993), p. 218

10. C.S. Covil, A.E. Skinner, Jet grouting: a review of some of the operating parameters that form the basis of the jet grouting process (Thomas Telford, London, 1994), p. 649

11. P. Croce, A. Flora, Analysis of single-fluid. JGG 50 (6), 739-748 (2000)

12. P. Croce, A. Flora, G. Modoni, Jet Grouting. Technology (CRC Press Taylor \& Francis Group, New York, 2014), p. 298.

13. H. Vleeschauwer, G. Maertens, Jet grouting: State of the art in Belgium, in Proceedings of the Conference 'Grouting-Soil improvementGeosystem including reinforcement', FGS, (Helsinki, 2000), pp. 145-156

14. J. Morey, F. Mathieu, Le procédé "JetPlus" optimise le jet grouting (SIS l'Amélioration des Sols en Place, Paris, 2004), pp. 245-261

15. H. Imanishi, Y. Yamauchi, Ground behavior during soil imprivement by Jey Grouting. GDM, 133-136 (1996)

16. I. Korobiichuk, V. Korobiichuk, P. Hájek, P. Kokeš, A. Juś, R. Szewczyk, Investigation of leznikovskiy granite by ultrasonic methods. AM. Sc. 63(1), 75-82 (2018). doi: $10.24425 / 118886$

17. V. Korobiichuk, Study of ultrasonic characteristics of Ukraine red granites at low temperatures. AISC 543, 653-658 (2017). doi:10.1007/978-3-319-48923-0_69

18. V. Korobiichuk, V. Kravets, R. Sobolevskyi, A. Han, V. Vapnichna, Weakening of rock strength under the action of cyclic dynamic loads.

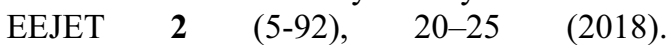
doi:10.15587/1729-4061.2018.127847

19. O. Terentiev, K. Tkachuk, O. Tverda, A. Kleshchov, Mathematical model of the reverse water post purification at mining enterprises when using electromagnetic focusing of contaminants. EEJET 1 (10-91), 11-16 (2018). doi:10.15587/1729-4061.2018.122000

20. O. Terentiev, K. Tkachuk, O. Tverda, A. Kleshchov, Electromagnetic focusing of impurities in water purification. EEJET 4 (1082), 10-15 (2016). doi:10.15587/17294061.2016.75251

21. R. Sobolevskyi, I. Korobiichuk, M. Nowicki, R. Szewczyk, V. Shlapak, Spatial Modeling of the Influence of Mining-Geometric Indices on the Efficiency of Mining. AMS 62 (4), 857-869 (2017). doi:10.1515/amsc-2017-0059

22. C. Dogruoz, O. Tolkach, R. Sobolevskyi, A. Nieto, Investigation of pyrophyllite deposits using multifactorial modeling method and 
complex quality index in Ukraine. EES 76 (23), 784 (2017). doi:10.1007/s12665-017-7153-0

23. S. Markov, M. Tyulenev, O. Litvin, E. Tyuleneva, Innovative numerical modelling of technogenic rock arrays structure. E3S Web of

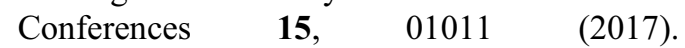
doi:10.1051/e3sconf/20171501011

24. S. Kravets, V. Suponyev, O. Rieznikov, F. Kosyak, D. Klets, O. Chevychelova, Determination of the resistance of the cylindrical-tubular drill for trenchless laying of underground communications. EEJET 3 (7-93), 64-70 (2018). doi:10.15587/17294061.2018.131838

25. Y. Malanchuk, V. Korniienko, L. Malanchuk, $\mathrm{V}$. Zaiets, Research into the moisture influence on the physical-chemical tuff-stone characteristics in basalt quarries of the RivneVolyn region. E3S Web of Conferences 201, 01036 (2020)

26. N.I. Stupnik, S.O. Popov, V.A. Azaryan, F.I. Karamanits, Research of parameters of development of deformation processes in underground excavations, using an automated laser scanning systems. GZ 5, 70-73 (2014)

27. V.P. Krasnov, T.V. Kurbet, I.V. Davydova, Z.M. Shelest, O.V. Zhukovsky, I.D. Ivanyuk, Dynamics of Cs content in the bark of frangula alnus mill, in the forests of Ukrainian Polissia. NPAE 19 (3), 258-264 (2018)

28. H. Kanematsu, High pressure jet grouting method. CConst. 21 (13), 136-147 (1980) 